\title{
eCHAT for Lifestyle and Mental Health Screening in Primary Care
}

\author{
Felicity Goodyear-Smith, MBCbB, \\ $M D, F R N Z C G P$ \\ Jim Warren, PbD \\ Minja Bojic \\ Angela Chong, BBus, RGN \\ Department of General Practice \& Primary \\ Health Care, Faculty of Medicine \& Health \\ Science, University of Auckland, New \\ Zealand
}

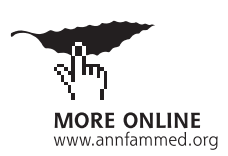

Conflicts of interest: authors report none.

\section{CORRESPONDING AUTHOR}

Felicity Goodyear-Smith, $M B C b B, M D$, FRNZCGP

Department of General Practice \& Primary Health Care

Faculty of Medicine \& Health Science University of Auckland

PB 92019 Auckland, New Zealand f.goodyear-smith@auckland.ac.nz

\begin{abstract}
PURPOSE Early detection and management of unhealthy behaviors and mental health issues in primary care has the potential to prevent or ameliorate many chronic diseases and increase patients' well-being. This study aimed to assess the feasibility and acceptability of the systematic use of a Web-based eCHAT (electronic Case-finding and Help Assessment Tool) screening patients for problematic drinking, smoking, and other drug use, gambling, exposure to abuse, anxiety, depression, anger control, and physical inactivity, and whether they want help with these issues. Patients self-administered eCHAT on an iPad in the waiting room and received summarized results, including relevant scores and interpretations, which could be accessed by a family physician on the website and in the electronic health record (EHR) at the point of care.
\end{abstract}

METHODS We conducted a mixed method feasibility and acceptability study in 2 general practices in Auckland, New Zealand. Participants were consecutive adult patients attending the practice during a 2-week period, as well as all practice staff. Patients completed eCHAT, doctors accessed the summarized reports. Outcome measures were patients' responses to eCHAT, and patients' written and staff recorded interview feedback.

RESULTS Of the 233 invited patients, 196 (84\%) completed eCHAT and received feedback. Domains where patients wanted immediate help were anxiety $(9 \%)$, depression (7\%), physical activity (6\%), and smoking (5\%), which was not overwhelming for physicians to address. Most patients found the iPad easy to use, and the questions easy to understand and appropriate; they did not object to questions. Feedback from 7 doctors, 2 practice managers, 4 nurses, and 5 receptionists was generally positive. Practices continue to use eCHAT regularly since the research was completed.

CONCLUSIONS eCHAT is an acceptable and feasible means of systemic screening patients for unhealthy behaviors and negative mood states and is easily integrated into the primary care electronic health record.

Ann Fam Med 2013;460-466. doi:10.1370/afm.1512.

\section{INTRODUCTION}

U nhealthy behaviors and mental health issues are major contributors to the burden of chronic disease suffered by many primary care patients. Early detection and helping patients in self-management can assist in primary and secondary prevention.

We developed the paper-based CHAT (Case-finding and Help Assessment Tool) for systematic assessment of lifestyle risk factors (smoking, problematic drinking, other drug use, gambling, exposure to abuse, physical inactivity) and mental health issues (depression, anxiety, anger control), which we evaluated in a number of primary care and community settings, ${ }^{1-4}$ and validated against a composite reference standard. ${ }^{5}$ A key component of CHAT is the help question, which asks patients whether they would like help, either during this visit or at a later date. This patient-centered approach facilitates shared decision making and self-management. We have shown that the help question significantly improves the specificity of the test. ${ }^{6-8}$ 
We subsequently developed an electronic version (eCHAT) to be used on a touch screen computer kiosk in the waiting room of a family practice. During a feasibility and acceptability study, most patients found the touch screen easy to use and the eCHAT questions clearly phrased and easy to understand, and that there were minimal objections to the questions being asked and minimal concerns about privacy with the process. ${ }^{9}$ This version was integrated directly into 1 of the 4 main electronic health records (EHRs) used by New Zealand family physicians; however, we decided a Web-based version would be more flexible.

The current eCHAT is self-administered on a tablet computer (eg, an iPad) in the waiting room, and the summarized results, including relevant scores and interpretations, where available, can be accessed by the family physician on the website and then downloaded into the EHR at the point-of-care. The clinicians have the choice or reading the summarized reports off the website, cutting and pasting these into the clinical notes, or clicking a button to load results into the EHR, entered in the screening and diagnosis fields. A red alert is provided if the patient's responses are positive for self-harm.

The digital nature of eCHAT allows for additional tools to be completed where relevant. If patients respond positively to the smoking, drinking, or other drug questions, they are administered the relevant World Health Organization Alcohol, Smoking and Substance Involvement Screening Test (ASSIST) ${ }_{1}^{10}$ and their responses scored and interpreted and provided in the clinician's summary. Similarly, positive answers to the depression and anxiety questions trigger the Patient Health Questionnaire for Depression (PHQ9) ${ }^{11}$ and the Generalized Anxiety Disorder Assessment (GAD-7) ${ }_{1}^{12}$ respectively. The help question is asked after positive responses in any of the 9 domains. The CHAT is available as an online Supplemental Appendix in the Annals of Family Medicine (http://www.annfammed. org/content/suppl/2009/05/07/7.3.239.DC1/GoodyearSmith_Supp_App.pdf) and the added tools (ASSIST, PHQ-9 and GAD-7) are in the public domain.

There is support in North America for such a tool. A recent US study identified support by stakeholders, including primary health care clinicians and patients of patient-reported data reflecting health behaviors and psychosocial issues being included in the EHR. ${ }^{13}$ Krist el al identify that information about health behaviors could be one of the most appropriate types of information provided by patients through a patient-centered personal health record portal. ${ }^{14} \mathrm{~A}$ study of standardized, brief practical health behavior (diet, physical activity, smoking, alcohol consumption) measures used across 7 practice-based research networks found modest improvements after interven- tion but concluded variations in implementation and instrumentation performance needed attention, which eCHAT would address. ${ }^{15}$

Primary care is the arena for improving population health. Barbara Starfield made the case that family physicians must be in the forefront of health care reform. ${ }^{16}$ She identified that primary health care needs to be accessible, person-focused over time, comprehensive, and coordinated..$^{17}$ This approach is in line with the development of the patient-centered medical home, defined as "an approach to providing comprehensive primary care...that facilitates partnerships between individual patients and their personal providers and, when appropriate, the patient's family." ${ }^{\prime 18-20}$ The 2010 Patient Protection and Affordable Care Act seeks to strengthen the primary care foundation in the United States through the use of innovative delivery models, such as the patient-centered medical home, ${ }^{21}$ based on the following principles:

- Patients having an on-going relationship with a personal physician trained to provide first-contact, continuous and comprehensive care

- A physician-led practice team approach; a whole person orientation with the personal physician responsible for providing for all the patient's health care needs or arranging appropriate care with other professionals

- Coordinated and/or integrated care across specialists, hospitals, and community agencies

- Quality and safety assurance by a care planning process, evidence-based medicine, clinical decision-support tools, performance measurement, active participation of patients in decision making, information technology, quality improvement activities, and other measures

- Enhanced access to care, such as new options for patient-clinician communication

eCHAT facilitates development of the patient-centered medical home. Because information is collected, analyzed automatically, and transferred seamlessly to EHR in real time to be accessed by the clinician, it is an efficient and cost-effective way of assessing some of patients' major lifestyle health risks. The time needed to identify problematic lifestyle behaviors and mental health issues is reduced, because eCHAT can be selfadministered in the waiting room before the visit. It further minimizes the chance of missing opportunities to provide early health care. eCHAT puts the patient, not the disease, in the center with a whole-person orientation. The questions on the eCHAT application greatly enhance the potential for clinicians to accurately identify patients' needs around such sensitive mental health issues as depression, domestic violence, and alcohol or illicit drug use. 
Our aim for this study was to assess the feasibility of the systematic use of the Web-based eCHAT selfadministered by patients in the waiting room, with summarized results accessed by family physicians during the ensuing visit, and to gauge the acceptability of this tool by patients, physicians, and other practice staff.

\section{METHODS}

Our study setting was 2 family practices in Auckland, New Zealand, between November 2011 and February 2012. Neither of the 2 practices had previously participated in CHAT or eCHAT research. They were selected because one had a particular interest in mental health issues and a patient profile of a relatively high socioeconomic status, and the other was in a relatively deprived neighborhood with a large number of patients who had substance misuse issues. In both practices over a 2- to 3-week period, the research assistant approached consecutive adult patients (aged 16 years and older) in the waiting room and invited them to participate in the study. Exclusion criteria included inability to communicate in English, impaired mental status (such as dementia) to the extent that they could not meaningfully participate, and previous recruitment in the study. Consenting patients selfadministered the eCHAT on an iPad. During their consultation, their family physician had access to their responses and relevant scores, using the eCHAT Webbased report followed by the option to download outcomes into the EHR.

Although the demographic characteristics of individual patients were not collected, the practices differed with respect to socioeconomic status, and enrollment by consecutive patients is likely to have meant that they represented the overall demographic of the practice population.

We used a multistrand mixed method (quantitative and qualitative) study design. We collated anonymized eCHAT responses from recruited patients extracted from the eCHAT database on the website. After the consultation, the patient completed a feedback form with both quantitative (yes/no) and free-text responses (see the Supplemental Appendix at http://annfammed.

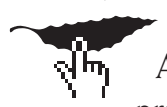
org/content/11/5/460/suppl/DC1 for questions). At the end of patient data collection from each practice, the research assistant invited all staff to participate in face-to-face, audio-recorded semistructured interviews, which were then transcribed.

We analyzed quantitative data using descriptive statistics. Two researchers read and re-read qualitative data to identify themes, which they then indepen-

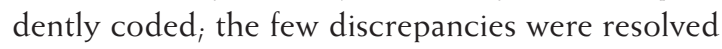
through adjudication.
Ethical approval was obtained from the Auckland Northern Y Regional Ethics Committee (reference NTY/11/10/102). Subsequent to the study phase both practices continue to implement eCHAT screening with their patients.

\section{RESULTS}

In total, 233 patients were invited to participate (practice $\mathrm{A}=127$; practice $\mathrm{B}=106$ ) of whom 211 consented, for a $91 \%$ response rate, and 196 patients both completed the eCHAT and provided feedback on the

\begin{tabular}{|lc|}
\hline $\begin{array}{l}\text { Table 1. Nonrespondents From 233 Invited } \\
\text { Participants }\end{array}$ \\
\hline Characteristic & No. (\%) \\
\hline Total nonrespondents & $37(15)$ \\
Declined, and reasons for declining & $22(9)$ \\
"Did not feel like it"/"Can't be bothered" & 4 \\
Felt too sick & 4 \\
Doctor already has this information & 2 \\
Vision problems & 2 \\
No reason given & 2 \\
Not at the doctors to talk about self-coming & 1 \\
in regarding a family member & \\
Possible chickenpox infection-not wanting to touch & 1 \\
iPad because might be infectious & 1 \\
Because of their condition & 1 \\
Too busy & 1 \\
Data utilization concerns & 1 \\
Not interested in at the moment but thinks & \\
it is a good idea & 1 \\
Did not want to discuss drug use with doctor & 1 \\
Not comfortable with information technology, iPad & 1 \\
Completed eCHAT, but time restraints prevented & \\
feedback & \\
\hline
\end{tabular}

Table 2. eCHAT Responses

\begin{tabular}{|c|c|c|c|c|c|}
\hline \multirow[b]{2}{*}{$\begin{array}{l}\text { eCHAT } \\
\text { Domains }\end{array}$} & \multirow[b]{2}{*}{$\begin{array}{l}\text { Responses } \\
\text { No. }\end{array}$} & \multirow[b]{2}{*}{$\begin{array}{c}\text { Positive } \\
\text { Score } \\
\text { No. (\%) }\end{array}$} & \multicolumn{3}{|c|}{$\begin{array}{l}\text { Help Question } \\
\text { Responses }\end{array}$} \\
\hline & & & No & $\begin{array}{l}\text { Yes, } \\
\text { But Not } \\
\text { Today }\end{array}$ & Yes \\
\hline Smoking & 196 & $29(15)^{\mathrm{a}}$ & 7 & 12 & 10 \\
\hline Drinking & 196 & $63(32)^{a}$ & 59 & 1 & 3 \\
\hline Drugs & 195 & $6(3)^{a}$ & 3 & 1 & 4 \\
\hline Gambling & 187 & $2(1)$ & 2 & - & - \\
\hline Depression & 187 & $29(16)^{a}$ & 11 & 4 & 14 \\
\hline Anxiety & 185 & $53(29)^{a}$ & 30 & 6 & 17 \\
\hline Abuse & 184 & $19(10)$ & 16 & 2 & 1 \\
\hline Anger & 182 & $20(11)$ & 15 & 2 & 3 \\
\hline Exercise & 181 & $75(41)$ & 58 & 6 & 11 \\
\hline \multicolumn{6}{|c|}{$\begin{array}{l}\text { ASSIST = Alcohol, Smoking and Substance Involvement Screening Test; } \\
\text { GAD-7 = Generalized Anxiety Disorder Assessment; PHQ-9 = Patient Health } \\
\text { Questionnaire for Depression. }\end{array}$} \\
\hline \multicolumn{6}{|c|}{ a Added tool (ASSIST, PHQ-9 or GAD-7) completed. } \\
\hline
\end{tabular}


Table 3. Quantitative Feedback From Patients

\begin{tabular}{lcc}
\hline Question & $\begin{array}{c}\text { Responses } \\
\text { No. }\end{array}$ & $\begin{array}{c}\text { Responded Yes } \\
\text { No. (\%) }\end{array}$ \\
\hline $\begin{array}{l}\text { Did you find the iPad easy to use? } \\
\text { Did you find all the questions } \\
\text { clearly phrased and easy to } \\
\text { understand? }\end{array}$ & 193 & $188(97)$ \\
$\begin{array}{l}\text { Do you think that this is an } \\
\text { appropriate thing for your fam- } \\
\text { ily doctor to be offering? }\end{array}$ & 188 & $176(90)$ \\
$\begin{array}{l}\text { Are there any questions you } \\
\text { object to being asked? } \\
\begin{array}{l}\text { Did you have any concerns about } \\
\text { privacy with the process? }\end{array}\end{array}$ & 192 & $7(4)$ \\
\hline
\end{tabular}

tool ( $84 \%$ of the invited sample) (Table 1). Attrition was due mainly to time constraints, with the research assistant unable to collect the feedback from every patient immediately after their visit with their doctor. Reasons that 22 patients declined to participate are shown in Table 1.

The responses patients gave to eCHAT are recorded in Table 2. The top domains where patients wanted immediate help were anxiety $(9 \%)$, depression (7\%), physical activity $(6 \%)$. and smoking (5\%), which their doctors did not find overwhelming. No patient wanted help during the consultation with more than one issue.

Table 4. Thematic Analysis of Patient Feedback

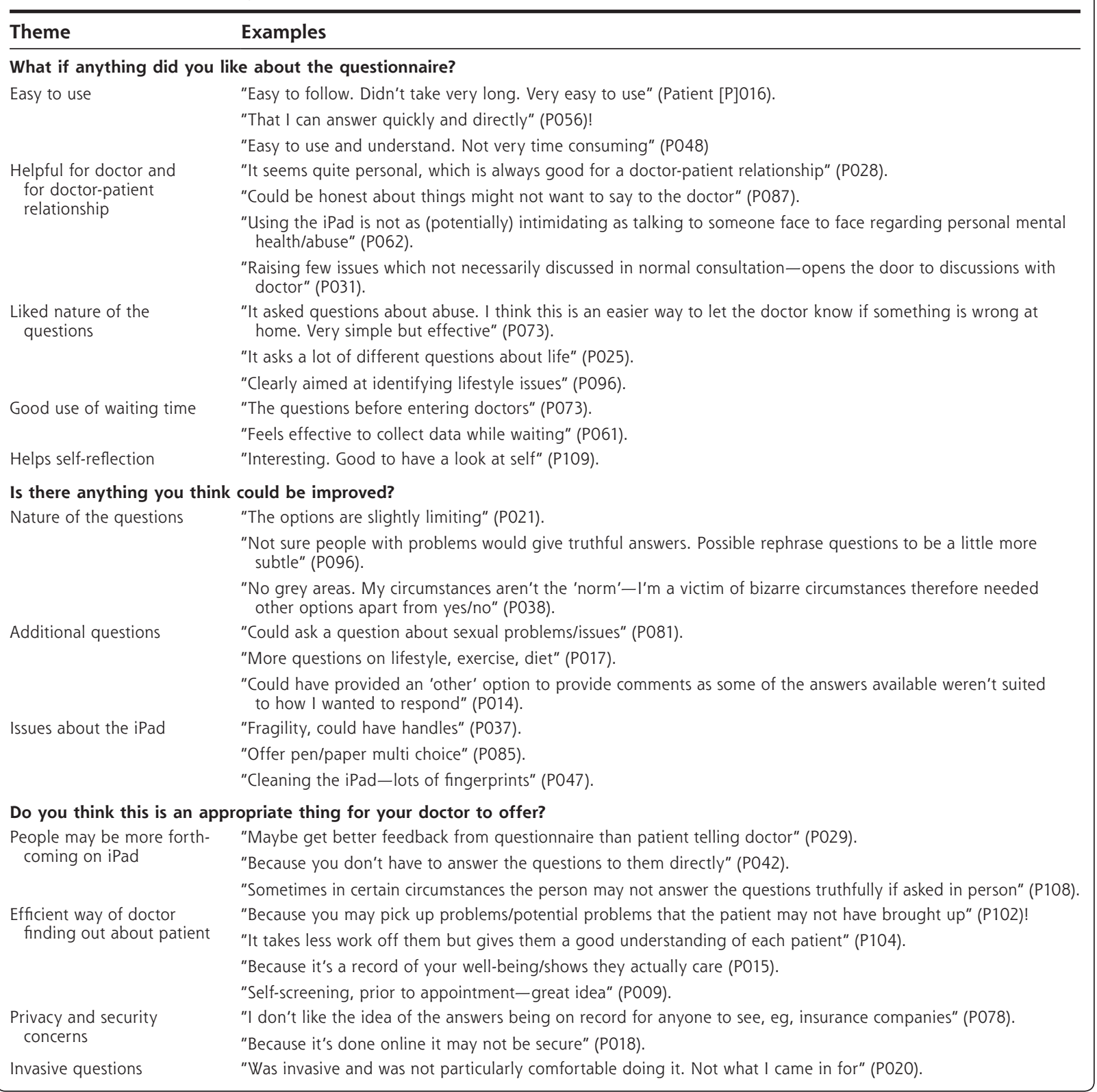


Most patients found eCHAT easy to use and did not object to the questions (Table 3). Themes derived from their qualitative responses are presented in Table 4. Although the majority were very positive about their eCHAT experience, a couple of patients expressed concerns about the security of Web-based data or the implications should their insurance company request this information. There was no significant difference (Fisher's exact 0.09), however, when comparing the number of positive eCHAT domains in the total participant group and those who did not answer the privacy question with those who had privacy concerns (Table 5).

Practice A staff consisted of 4 family physicians, 2 nurses, 3 receptionists, and 1 practice manager.
Practice B had 3 family physicians, 1 practice manager, and 2 nurses who also served as receptionists. Table 6 records the major emerging themes with examples from the 16 audio-recorded and transcribed staff interviews. In general, staff found the tool to be simple, quick, and easy to use; they liked the way their patients were screened, they valued the way it facilitated patient engagement; and they appreciated the way it integrated with the EHR at the point of care. A concern about insurance companies having access to eCHAT reports was raised by 1 doctor who chose not to download the results into the EHR for this reason. Although some staff believed it saved them time, others saw that it could lead to an extended consultation on occasion in the short-term, but in the longer term it was an efficient way of finding out and addressing patient needs. All 7 family physicians agreed that eCHAT could contribute to patient understanding in relation to their risky health behaviors or mental health issues through various interventions and self-management.

Table 6. Thematic Analysis of Staff Feedback

\begin{tabular}{|c|c|}
\hline Theme & Examples \\
\hline \multicolumn{2}{|c|}{ What if anything did you like about eCHAT? } \\
\hline Easy to use & "It's quite simplistic, it's straightforward, patients are responding very well to it" (Receptionist [R]01). \\
\hline $\begin{array}{l}\text { Electronic integra- } \\
\text { tion helpful }\end{array}$ & $\begin{array}{l}\text { "Very easy to upload into the [EHR]" (Family physician [FP]01). } \\
\text { "No forms to fill in" (R05). } \\
\text { "As opposed to a written form, is that it's straight in the notes" (Nurse [N]01). }\end{array}$ \\
\hline \multirow{3}{*}{$\begin{array}{l}\text { Valuable } \\
\text { screening }\end{array}$} & $\begin{array}{l}\text { "I like the potential it has to help people to disclose symptoms that they mightn't be able to tell me in the consultation" } \\
\text { (FP03) }\end{array}$ \\
\hline & "Patients find it easy to disclose problems on the eCHAT which they wouldn't have necessarily have brought up" (FP02). \\
\hline & $\begin{array}{l}\text { "Fast, productive method of getting screening. Which helps us do a lot of our programs, and know more about the } \\
\text { people" (N01). }\end{array}$ \\
\hline \multirow{3}{*}{$\begin{array}{l}\text { Contribute posi- } \\
\text { tively to time } \\
\text { with patients }\end{array}$} & "...because it cuts to the chase and it means the problem is there on the table right at the start of the consultation" (FP01). \\
\hline & $\begin{array}{l}\text { "It couldn't be more efficient, a lot of that information... if you tried to extract it yourself in the course of the consultation } \\
\text { it would just blow out hideously, you couldn't do it. And so, of course, often we don't, and you just tend to fancy that } \\
\text { you, you know, acquire that information or if it's relevant you think you know it but sometimes you do and sometimes } \\
\text { you don't. I think it's really plugging some really important holes and it's going to have a real efficiency to what we're } \\
\text { doing in terms of...getting people's important underlying problems to the surface sooner rather than later" (FP03). }\end{array}$ \\
\hline & "In a sense creates more work, but that's what we're here for" (FP04). \\
\hline \multicolumn{2}{|c|}{ Is there anything you think could be improved? } \\
\hline $\begin{array}{l}\text { Concerns about } \\
\text { insurance com- } \\
\text { pany access }\end{array}$ & $\begin{array}{l}\text { "The insurance companies now have access to our notes... it asks 'have you taken drugs', and I know that the insurance com- } \\
\text { panies are very interested in that, and I don't know how selective they may be in } 5 \text { or } 10 \text { years' time" (FP05). }\end{array}$ \\
\hline $\begin{array}{l}\text { Electronic } \\
\text { notification }\end{array}$ & "An alert on the patient's file that it has been done" (R05). \\
\hline Font size & "He said he couldn't see it very well, he had to go and get his reading glasses, so maybe a bit bigger writing, brighter" (R03)? \\
\hline $\begin{array}{l}\text { Provision of addi- } \\
\text { tional services }\end{array}$ & $\begin{array}{l}\text { "Funding. Because a lot of the issues that it's going to tap into are ones that are going to require extended mental health } \\
\text { type consultations and in some instances referral to clinical psychologists" (FPO3). }\end{array}$ \\
\hline
\end{tabular}




\section{DISCUSSION}

eCHAT was found to be an acceptable method of implementing systematic lifestyle and mental health screening in patients to general practice. With a more than $90 \%$ response rate, eCHAT screening is an effective means of identifying, managing, and documenting these issues. The help question further empowers patients to control the direction of their consultation. Evidence indicates that when a patient identifies an issue as a problem, it is more likely to be solved than when it is identified by their health care clinician. ${ }^{22} 23$

eCHAT screening offers an opportunity to improve documentation of lifestyle and mental health issues.

For instance, it was found previously that New Zealand general practice EHRs had smoking status recorded for less than $50 \%$ of adults, ${ }_{1}^{24}$ a rate can be improved through routine use of eCHAT. Interoperability of eCHAT with the EHR also allows for improved clinical coding, whereas without such a system many of the eCHAT areas, even if addressed, would be likely to be recorded only as free-text notes.

The potential for improved coding, however, has not gone unnoticed by patients and staff, both of whom raised concerns with respect to future access to the information, particularly by insurance companies. The concerns parallel issues arising with the increasing documentation of genomic data and how this recording in the clinical notes may affect patients' future equity of health care access. ${ }^{25,26}$ Such concerns may be difficult to alleviate: in the United States, where 17 months after introduction of the Genetic Information Nondiscrimination Act of 2008 (GINA) it was found that physicians were only patchily aware of its protections, and awareness did not alleviate physician concerns regarding the risk of genetic discrimination. ${ }^{27}$ The collection, however, of lifestyle and mental health data that is worrying some patients and staff is already an issue intrinsic in the EHR $\mathrm{E}_{i}$ the systematic approach using eCHAT only brings this latent issue into sharper focus.

Although patients expressing negative feedback and concerns were in the minority, there were a few criticisms of the scope and form of questions, particularly in how such questions as physical activity offered "no grey areas."

Since the research phase, both practices have continued to use eCHAT at a relatively constant rate as part of routine practice during the past year. They are provided with regular feedback about their eCHAT usage. A regular e-mailed activity report logs how many they have conducted each week. One practice is using eCHAT on every adult patient and has averaged 13 per week over 40 weeks. The other practice uses eCHAT on selected patients (for example, all new patients, pregnant, not seen for 1 year, history of chronic illness, mental illness, or substance misuse) and has averaged 7 per week over 46 weeks.

\section{Strengths and Limitations}

Strengths of this study include the high response rate of patients agreeing to participate and feedback data obtained from 196 patients. A limitation is that, because of time constraints, not all consecutive patients who walked into the waiting room were able to be asked to participate in the study by the research assistant. As a result, our selection process was not a systematic way of recruiting patients, which could mean there is some bias in the data. Further, the eCHAT was piloted in 2 volunteer practices, which might not necessarily represent the range either of staffing arrangements, work flows, cultures, and technical configurations or of enthusiasm for such an innovation.

\section{Comparison With Our Previous Study}

We conducted a previous, smaller feasibility and acceptability study of a touch-screen (pre-iPad) computer-based eCHAT. ${ }^{9}$ In this current study, we had a larger number of participants with completed feedback forms (196 compared with 50). Results from the 2 studies are similar in that most patients found the iPad or touch-screen computer easy to use and the questions clearly phrased, and they had minimal objection to the questions or concerns about privacy. Our touchscreen study had a higher rate of patients declining to participate (26\%), whereas in this iPad study only $9 \%$ of patients did not want to complete the eCHAT. The ease of use of the iPad, its increased privacy due to its portability, and the novelty factor may be contributing factors to the lower decline rate.

\section{Implications}

From this study we have determined that the eCHAT can be easily incorporated into the family practice environment, as most patients, physicians, and other practice staff find it acceptable for use in this setting, and it is easily integrated into the EHR. The eCHAT is therefore an acceptable tool for systemic finding of cases of unhealthy behaviors and negative mood states in primary care.

\section{Future Developments}

Electronic links to stepped-care decision support is now being implemented. This provides for each domain a suite of self-management options (information sheets, help lines, URLs including eTherapies), physician-initiated treatments (brief interventions and medications), referral to community-based agencies, and finally to secondary services. Where patients can access their own EHR and complete eCHAT prior to 
presenting for their appointment, they will be able to access self-help and support options themselves and only consult their physician when they require a stepup in intervention.

The question remains as to whether systematic case-finding using eCHAT will lead to improved health outcomes. We propose conducting a clustered randomized trial to determine the effectiveness and costeffectiveness of systematically detecting and assisting patients to address the 9 eCHAT domains.

To read or post commentaries in response to this article, see it online at http://www.annfammed.org/content/11/5/460.

Submitted August 27, 2012; submitted, revised, November 13, 2012; accepted December 27, 2012.

Key words: primary health care; mass screening; life style; mental health; risk reduction behavior

Funding support: Funding for summer studentship provided by the Royal New Zealand College of General Practitioners and the University of Auckland.

Prior presentations: Poster presentation, North American Primary Care Research Group annual meeting, 2012.

Acknowledgments: We would like to thank the patients and practice staff who contributed to this study.

\section{References}

1. Goodyear-Smith F, Arroll B, Coupe N, Buetow S. Ethnic differences in mental health and lifestyle issues: results from multi-item general practice screening. N Z Med J. 2005;118(1212):U1374.

2. Goodyear-Smith F, Arroll B, Kerse N, et al. Primary care patients reporting concerns about their gambling frequently have other co-occurring lifestyle and mental health issues. BMC Fam Pract. 2006;7:25.

3. Goodyear-Smith F, Arroll B, Sullivan S, Elley R, Docherty B, Janes R. Lifestyle screening: development of an acceptable multi-item general practice tool. N Z Med J. 2004;117(1205):U1146.

4. Goodyear-Smith F, Arroll B, Tse S. Asian language school student and primary care patient responses to a screening tool detecting concerns about risky lifestyle behaviours. N Z Fam Physician. 2004;31(2):84-89.

5. Goodyear-Smith F, Coupe NM, Arroll B, Elley CR, Sullivan S, McGill AT. Case finding of lifestyle and mental health disorders in primary care: validation of the 'CHAT' tool. Br J Gen Pract. 2008;58(546):26-31.

6. Arroll B, Goodyear-Smith F, Kerse N, Fishman T, Gunn J. Effect of the addition of a "help" question to two screening questions on specificity for diagnosis of depression in general practice: diagnostic validity study. BMJ. 2005;331(7521):884.

7. Goodyear-Smith F, Arroll B, Coupe N. Asking for help is helpful: validation of a brief lifestyle and mood assessment tool in primary health care. Ann Fam Med. 2009;7(3):239-244.

8. Puddifoot S, Arroll B, Goodyear-Smith F, Kerse N, Fishman T, Gunn J. A new case-finding tool for anxiety: a pragmatic diagnostic validity study in primary care. Int J Psychiatry Med. 2007;37(4):71-81.
9. Warren J, Goodyear-Smith F, Miller D, et al. An integrated electronic lifestyle and mental health patient self-assessment for general practice: Design and initial field study. Health Care Inform Rev Online. 2010;14(4):18-25.

10. WHO ASSIST Working Group. The Alcohol, Smoking and Substance Involvement Screening Test (ASSIST): development, reliability and feasibility. Addiction. 2002;97(9):1183-1194.

11. Kroenke K, Spitzer RL, Williams JB. The PHQ-9: validity of a brief depression severity measure. J Gen Intern Med. 2001;16(9):606-613.

12. Spitzer RL, Kroenke K, Williams JBW, Löwe B. A brief measure for assessing generalized anxiety disorder: the GAD-7. Arch Intern Med. 2006;166(10):1092-1097.

13. Estabrooks PA, Boyle M, Emmons KM, et al. Harmonized patientreported data elements in the electronic health record: supporting meaningful use by primary care action on health behaviors and key psychosocial factors. J Am Med Inform Assoc. 2012;19(4):575-582.

14. Krist AH, Woolf SH. A vision for patient-centered health information systems. JAMA. 2011;305(3):300-301.

15. Fernald DH, Dickinson LM, Froshaug DB, et al. Improving multiple health risk behaviors in primary care: lessons from the Prescription for Health Common Measures, Better Outcomes (COMBO) study. J Am Board Fam Med. 2012;25(5):701-711.

16. Starfield B, Shi L, Macinko J. Contribution of primary care to health systems and health. Milbank Q. 2005;83(3):457-502.

17. Starfield B, Shi L. The medical home, access to care, and insurance: a review of evidence. Pediatrics. 2004;113(5)(Suppl):1493-1498.

18. American Academy of Family Physicians (AAFP), American Academy of Pediatrics (AAP), American College of Physicians (ACP), American Osteopathic Association (AOA). Joint Principles of the Patient Centered Medical Home. Washington DC: Patient Centered Primary Care Collaborative; 2007:3.

19. Backer LA. Building the case for the patient-centered medical home. Fam Pract Manag. 2009;16(1):14-18.

20. Nutting $P A$, Miller $W / L$, Crabtree $B F$, Jaén $C R$, Stewart EE, Stange KC. Initial lessons from the first national demonstration project on practice transformation to a patient-centered medical home. Ann Fam Med. 2009;7(3):254-260.

21. Davis K, Abrams M, Stremikis K. How the Affordable Care Act will strengthen the nation's primary care foundation. J Gen Intern Med. 2011;26(10):1201-1203.

22. Enguidanos S, Coulourides Kogan A, Keefe B, Geron SM, Katz L. Patient-centered approach to building problem solving skills among older primary care patients: problems identified and resolved. J Gerontol Soc Work. 2011;54(3):276-291.

23. Maly RC, Bourque LB, Engelhardt RF. A randomized controlled trial of facilitating information giving to patients with chronic medical conditions: effects on outcomes of care. J Fam Pract. 1999;48(5):356-363.

24. Selak V, Wells S, Whittaker R, Stewart A. Smoking status recording in GP electronic records: the unrealised potential. Inform Prim Care. 2006;14(4):235-241, discussion 242-245.

25. McClellan KA, Avard D, Simard J, Knoppers BM. Personalized medicine and access to health care: potential for inequitable access? Eur J Hum Genet. 2013;21(2)143-147.

26. Idemyor V. Genomic medicine: health care issues and the unresolved ethical and social dilemmas. Am J Ther. 2012 Jun 16 [epub ahead of print].

27. Laedtke AL, O'Neill SM, Rubinstein WS, Vogel KJ. Family physicians' awareness and knowledge of the Genetic Information NonDiscrimination Act (GINA). J Genet Couns. 2012;21(2):345-352. 